\title{
Role of Consolidative Thoracic Radiotherapy for Extensive-stage Small Cell Lung Cancer: Trod Thoracic Oncology Study Group 08-006 Multi-institutional Study
}

\author{
(1) Güler YAVAŞ, ${ }^{1}$ (D) Esra KORKMAZ KIRAKLI, ${ }^{2}$ (D) Meltem DAĞDELEN, ${ }^{3}$ (i) Erkan TOPKAN, ${ }^{4}$ \\ (1) Mert SAYNAK, ${ }^{5}$ (i) Fazilet ÖNER DiNÇBAŞ, ${ }^{3}$ (i) Yurday ÖZDEMIR, ${ }^{5}$ (i) Çağdaş YAVAŞ, ${ }^{1}$ \\ (D) Sümerya Duru BİRGi, 6 (1) Serap AKYÜREK ${ }^{6}$ \\ 'Department of Radiation Oncology, Baskent University, Ankara-Turkey \\ 2Department of Radiation Oncology, University of Health Sciences, Dr. Suat Seren Chest Diseases and Surgery Training and Research \\ Hospital, İzmir-Turkey \\ ${ }^{3}$ Department of Radiation Oncology, Istanbul University-Cerrahpaşa, Cerrahpasa Faculty of Medicine, Istanbul-Turkey \\ ${ }^{4}$ Department of Radiation Oncology, Baskent University, Adana Dr. Turgut Noyan Application and Research Center, Adana-Turkey \\ ${ }^{5}$ Department of Radiation Oncology, Trakya University, Edirne-Turkey \\ ${ }^{6}$ Department of Radiation Oncology, Ankara University, Ankara-Turkey
}

\section{OBJECTIVE}

We aimed to evaluate the role of consolidative thoracic radiotherapy (TRT) in patients with extensivestage small cell lung cancer (ES-SCLC).

\section{METHODS}

The clinical data for 151 patients with the diagnosis of ES-SCLC treated with consolidative TRT from six different hospitals from Turkey analyzed.

\section{RESULTS}

The median age of the patients was 61 years (range 36-83 years). The median dose of radiotherapy (RT) was 45 Gy (range: 30-66 Gy) applied in median 25 fractions (range 10-34 fractions). For 151 assessable patients, the median survival time (MST) was 14 months (range: 12.6-15.3). The patients who has complete response and partial response had 16 months, and 14 months of MST. In multivariate analyses prophylactic cranial irradiation (PCI) $(\mathrm{p}=0.011)$, female gender $(\mathrm{p}=0.017)$, and comorbidity $(\mathrm{p}=0.006)$ were found as significant parameters associated with survival. The MSTs were 12 months in patients without comorbidity, and 16 months for the patients with at least one comorbid disease. The patients who received PCI had improved MSTs when compared the ones without PCI (16 months vs. 12 months). There was a trend towards improved overall survival times in patients who received EQD2 $\geq 47$ Gy RT doses $(\mathrm{p}=0.08)$.

\section{CONCLUSION}

Female gender, use of PCI, and unavailability of comorbid disease were associated with improved survival in ES-SLCL patients. There was a trend towards overall survival times in patients who received $\geq 47$ Gy EQD2 doses; however, we believe that this statistical insignificance was related to our limited patient numbers.

Keywords: Consolidative; extensive stage; small-cell lung cancer; survival; thoracic radiotherapy. Copyright $\odot$ 2022, Turkish Society for Radiation Oncology 


\section{Introduction}

Small cell lung cancer (SCLC) is a neuroendocrine tumor that represents about $12-20 \%$ of all lung cancers.[1,2] SCLC is characterized by its high growth fraction, early development of metastases, and development of treatment resistance particularly for the patients with metastatic disease.[3] SCLC usually presents with disseminated disease as approximately $60-70 \%$ of the patients diagnosed with metastatic disease.[4] Although the response rates for initial chemotherapy (CT) is high, extensive-stage (ES)SCLC commonly relapses within months, and unfortunately, the survival of SCLC is very poor.

The main problem of ES-SCLC patients after CT is intra-thoracic tumor recurrence since $75 \%$ of the patients had persisting intra-thoracic disease after CT, and approximately $90 \%$ of the patients had intra-thoracic progressive disease within the $1^{\text {st }}$ year after diagnosis. [5] Such high rate of intra-thoracic disease progression explains the need of local treatment in selected patients.

There are three randomized studies and two metaanalyses evaluating the role of thoracic radiotherapy (TRT) in patients with ES-SCLC who responded to CT.[6-9] Two of the randomized trials and one of the meta-analyses showed survival benefit of TRT. Therefore it is reasonable to use TRT for ES-SCLC patients, who responded to $\mathrm{CT}$ and have intrathoracic residual disease after CT. However there should be a subgroup of patients who may benefit from TRT most, and the factors affecting the response to TRT should be defined. In addition, the optimal dose, fractionation scheme, and the timing of TRT are still unknown. In this multicenter study of Turkish Society of Radiation Oncology, Lung Cancer Study group we aimed to evaluate the role of consolidative TRT for the patients with ES-SCLC.

\section{Materials and Methods}

\section{Patient Selection and Treatment Protocol}

We retrospectively reviewed electronic medical records for 151 ES-SCLC treated with consolidative TRT from six different academic hospitals from the Turkey. All patients were treated in accordance with the clinicians' practices and department policies. All the patients received neoadjuvant, adjuvant, or concomitant CT. The median dose of TRT was 45 Gy (range, 30-66 Gy), with a daily median fraction number of 25 (range, 10-34).

\section{Follow-up}

After completion of treatment, all patients were followed by treating physician and a medical oncologists.
The blood sample analyses and chest tomography were made at periodically, and additional radiological imaging was also performed when necessary. The follow-up period was every 3 months for the first 2 years, every 6 months between $2^{\text {nd }}$ and $5^{\text {th }}$ years, and annually thereafter.

\section{Statistical Analysis}

All statistical analyses were performed using standard software (SPSS version 22; SPSS Inc., Chicago, IL, USA). The primary outcomes of interest were OS and PFS. Time to death or progression was calculated as the period from the date of diagnosis to date of death or first clinical or imaging evidence of disease recurrence. Survival analyses were performed using the KaplanMeier method and compared using the log-rank test. The $\chi^{2}$ test or student's t-test were used to analyze the differences in clinical and pathological factors. Univariate analysis was performed via the log-rank test. Multivariate analysis was performed using the Cox proportional hazards model, using covariates with a $\mathrm{p}<0.10$ based on univariate analysis. All $\mathrm{p}<0.05$ were considered statistically significant.

\section{Results}

\section{Patient and Treatment Characteristics}

Between May 2001, and April 2020151 ES-SCLC patients who underwent consolidative TRT from six different academic hospitals from the Turkey were included in the study. The patient and tumor and treatment characteristics are summarized in Table 1 . There were 22 (14.6\%) female, and 129 (85.4\%) male patients. The median age of the patients was 61 years (range 36-83 years). Most of the patients had a performance score 1 (54.3\%) according to Eastern Cooperative Oncology Group (ECOG) scoring system. Eighty-seven (57.6\%) patients did not have any comorbid diseases, on the other hand, 24 (15.9\%) of the patients had $\geq 2$ co-morbid diseases. At baseline 5\%, 5-10\%, and $>10 \%$ weight loss were recorded in $9.9 \%, 9.3 \%$, and $13.9 \%$ of the patients, respectively. Most of the patients (62.9\%) had multiple metastases at the time of the diagnosis. Isolated liver, lung, and bone metastases were obtained in $7.3 \%, 15.2 \%$, and $14.6 \%$ of the patients, respectively.

The most common CT schedule was cisplatin and etoposide $(94.7 \%)$, and $73.5 \%$ of patients received 6 cycles. RT was applied after CT in 129 (85.4\%) patients, and 10 patients (6.6\%) received RT prior to CT because vena cava superior syndrome. The median dose of RT was 45 Gy (range: 30-66 Gy) applied in 
Table 1 Patient, tumor, and treatment characteristics for the entire cohort

\begin{tabular}{|c|c|}
\hline Characteristics & $\begin{array}{c}\text { Patients (\%) } \\
n=151\end{array}$ \\
\hline \multicolumn{2}{|l|}{ Gender } \\
\hline Female & $22(14.6)$ \\
\hline Male & $129(85.4)$ \\
\hline \multicolumn{2}{|l|}{ ECOG Performance Score } \\
\hline 0 & $33(21.9)$ \\
\hline 1 & $82(54.3)$ \\
\hline 2 & $32(21.2)$ \\
\hline 3 & $4(2.6)$ \\
\hline \multicolumn{2}{|l|}{ Co-morbidities } \\
\hline Absent & $87(57.6)$ \\
\hline COPD & $24(15.9)$ \\
\hline DM & $7(4.6)$ \\
\hline CAD & $8(5.3)$ \\
\hline CVD & $1(0.7)$ \\
\hline$\geq 2$ co-morbid disease & $24(15.9)$ \\
\hline \multicolumn{2}{|l|}{ Weight Loss } \\
\hline None & $101(66.9)$ \\
\hline $5 \%$ & $15(9.9)$ \\
\hline $5-10 \%$ & $14(9.3)$ \\
\hline$>10 \%$ & $21(13.9)$ \\
\hline \multicolumn{2}{|l|}{ Metastases } \\
\hline Liver & $11(7.3)$ \\
\hline Lung & $23(15.2)$ \\
\hline Bone & $22(14.6)$ \\
\hline Multiple & $95(62.9)$ \\
\hline \multicolumn{2}{|l|}{ RT technique } \\
\hline 3D-CRT & $95(62.9)$ \\
\hline IMRT & $40(26.5)$ \\
\hline $2 \mathrm{D}$ & $16(10.6)$ \\
\hline \multicolumn{2}{|l|}{$\mathrm{PCl}$} \\
\hline Present & $102(67.6)$ \\
\hline Absent & $49(32.4)$ \\
\hline
\end{tabular}

ECOG: Eastern Cooperative Oncology Group; COPD: Chronic obstructive pulmonary disease; DM: Diabetes mellitus; CAD: Coronary artery disease; CVD: Cerebrovascular disease; RT: Radiotherapy; 3d-CRT: 3-Dimensional conformal radiotherapy; IMRT: Intensity modulated radiotherapy; PCI: Prophylactic cranial radiotherapy

median 25 fractions (range 10-34 fractions). The most common used RT technique was 3-dimensional conformal RT (62.7 \%). The median dose of $25 \mathrm{~Gy}$ (range, 25-36 Gy) prophylactic cranial irradiation (PCI) was applied to $102(67.5 \%)$ of the patients. PCI was applied before and during TRT in 34 (22.5\%), and $3(2 \%)$ of the patients, respectively.

\section{Treatment Outcomes}

For 151 assessable patients, the median survival time (MST) was 14 months (range: 12.6-15.3). After initial
CT $44(29.1 \%)$ patients had a complete response, and 79 (52.3\%) patients had a partial response. The patients who had a complete response and partial response had 16 months, and 14 months of MST. In multivariate analyses PCI $(\mathrm{p}=0.011)$, female gender $(\mathrm{p}=0.017)$, and comorbidity $(\mathrm{p}=0.006)$ were found as significant parameters associated with survival. The patients who received PCI had improved MSTs when compared the ones without PCI (16 months vs. 12 months) (Fig. 1). The MSTs were 12 months in patients without comorbidity, and 16 months for the patients with at least one comorbid disease (Fig. 2). The MSTs for the female, and male patients were 20 months, and 14 months, re-

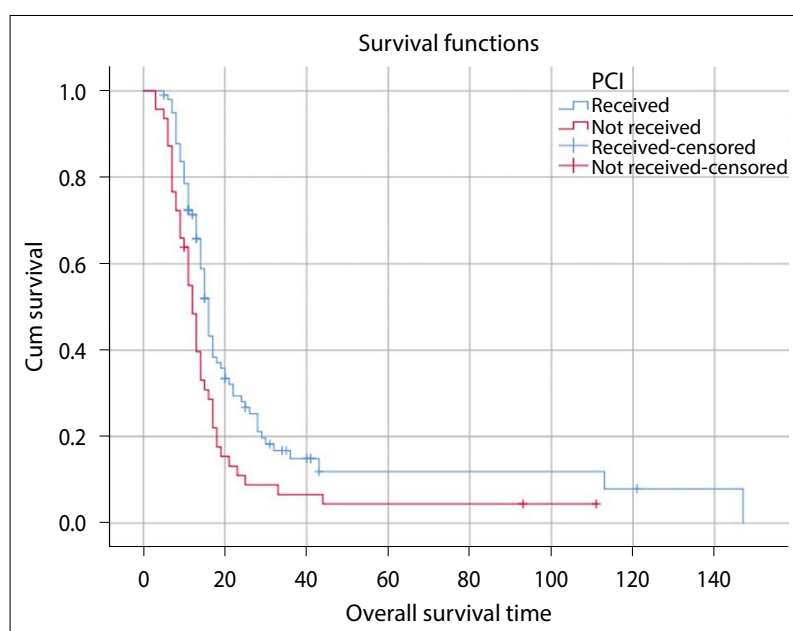

Fig. 1. Kaplan-Meier plots of overall survival for patients who received PCI (blue line) and not received PCI (red line).

PCI: Prophylactic cranial radiotherapy.

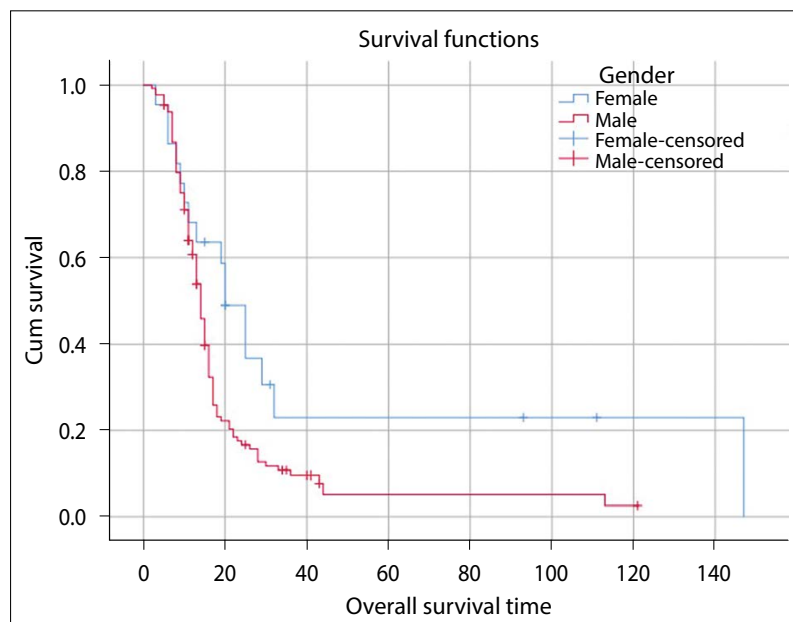

Fig. 2. Kaplan-Meier plots of overall survival for female patients (blue line) and male patients (red line). 


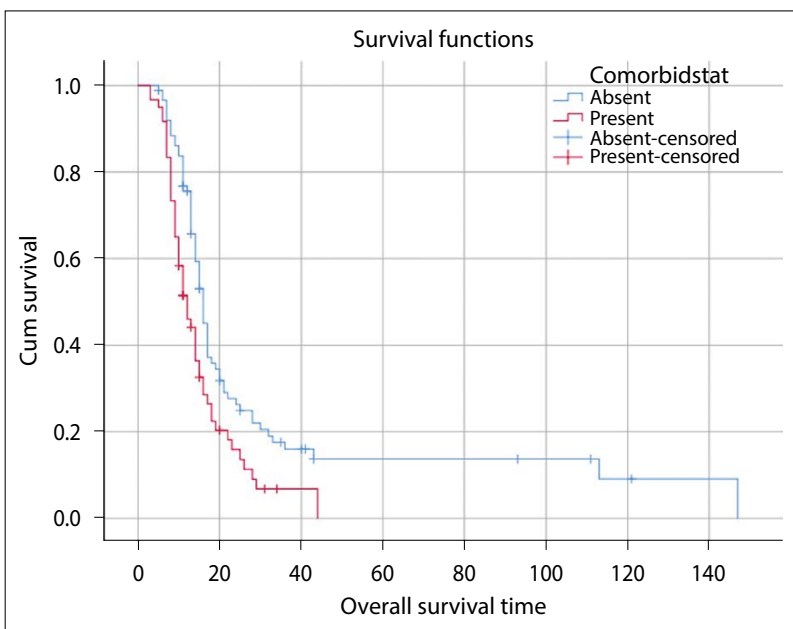

Fig. 3. Kaplan-Meier plots of overall survival for patients who did not have any co-morbidity (blue line) and who had co-morbidity (red line).

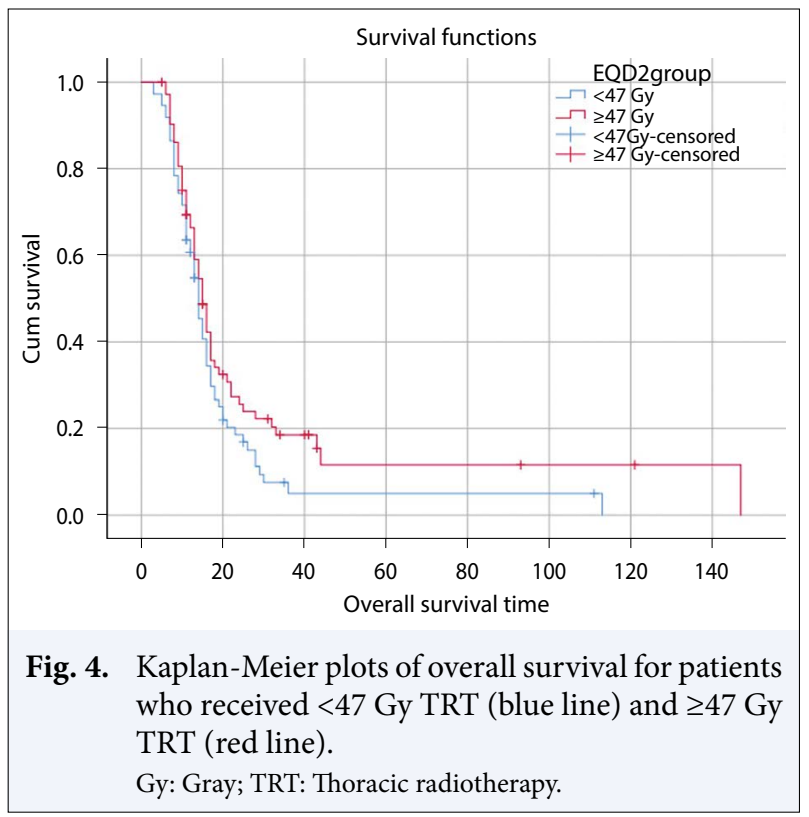

spectively (Fig. 3). There was a trend toward improved overall survival times in patients who received EQD2 $\geq 47$ Gy RT doses ( $\mathrm{p}=0.08$ ) (Fig. 4).

\section{Toxicity}

Table 2 shows both hematological, and non-hematological toxicities for entire cohort. Grade 1-2 leukopenia, thrombocytopenia, and anemia were observed in $6.6 \%, 3.3 \%$, and $17.8 \%$ of the patients. There weren't any grade 3 nausea, vomiting, esophagitis, and fatigue. Grade 2 nausea, vomiting, esophagitis, and fatigue rates were $14.6 \%, 9.3 \%, 43 \%$, and $54.3 \%$, respectively. Radi-

\begin{tabular}{|cc}
\hline Table 2 Treatment-related toxicities & \\
\hline Toxicity & Frequency (\%) \\
\hline $\begin{array}{c}\text { Hematological toxicities } \\
\text { Leukopenia }\end{array}$ \\
Absent & \\
Grade 1 & $139(92.1)$ \\
Grade 2 & $7(4.6)$ \\
Grade 3 & $3(2.0)$ \\
Thrombocytopenia & $2(1.3)$ \\
Absent & \\
Grade 1 & $145(96)$ \\
Grade 2 & $3(2.0)$ \\
Grade 3 & $2(1.3)$ \\
Anemia & $3(0.7)$ \\
Absent & \\
Grade 1 & $123(81.5)$ \\
Grade 2 & $20(13.2)$ \\
Grade 3 & $7(4.6)$ \\
Non-Hematological toxicities & $1(0.7)$ \\
Nausea & \\
Absent & \\
Grade 1 & $129(85.4)$ \\
Grade 2 & $14(9.3)$ \\
Vomiting & $8(5.3)$ \\
Absent & \\
Grade 1 & $137(93.7)$ \\
Grade 2 & $6(4.0)$ \\
Esophagitis & $8(5.3)$ \\
Absent & \\
Grade 1 & $71(47.0)$ \\
Grade 2 & $41(27.2)$ \\
Fatigue & $39(25.8)$ \\
Absent & \\
Grade 1 & $69(45.7)$ \\
Grade 2 & $56(37.1)$ \\
\hline & $26(17.2)$ \\
\hline
\end{tabular}

ation pneumonia was observed in 17 (11.3\%) patients, and all symptoms were relieved with steroid treatment.

\section{Discussion}

In the current study, we discovered that consolidative TRT is safe and tolerable in patients with ES-SCLC patients who responded CT. Female gender, use of PCI, and unavailability of comorbid disease were associated with improved survival in ES-SLCL patients. The RT dose $\geq 47$ Gy has associated a trend towards overall survival times.

ES-SCLC patients who have residual thoracic disease after initial systemic CT may benefit from TRT in terms of survival times. Table 3 shows the randomized trials investigating the role of consolidative TRT in ES- 
Table 3 Randomized trials investigating the role of consolidative TRT in ES-SCLC patients

\begin{tabular}{|c|c|c|c|c|c|c|c|}
\hline $\begin{array}{l}\text { Author, } \\
\text { year }\end{array}$ & $\mathbf{N}$ & $\begin{array}{c}\text { RCT } \\
\text { design }\end{array}$ & $\mathbf{C T}$ & $\begin{array}{c}\mathrm{RT} / \mathrm{CT} \\
\text { sequence }\end{array}$ & TRT scheme & $\begin{array}{l}\mathrm{PCl} \\
\text { dose }\end{array}$ & $\begin{array}{l}\text { Results/ } \\
\text { comments }\end{array}$ \\
\hline $\begin{array}{l}\text { Jeremic et al., } \\
\text { 1999[6] }\end{array}$ & 109 & Phase III & $\begin{array}{c}\text { PE } \\
\text { (3 cycles) }\end{array}$ & $\mathrm{CT} \rightarrow \mathrm{RT}$ & $\begin{array}{l}54 \mathrm{~Gy} / 36 \mathrm{fr} / 18 \text { days to } \\
\text { gross chest disease, } \\
\text { ipsilateral hilum, } \\
\text { mediastinum, bilateral } \\
\text { supraclavicular fossae }\end{array}$ & $25 \mathrm{~Gy} / 10 \mathrm{fr}$ & $\begin{array}{l}\text { Improved median OS } \\
\text { (17 vs. } 11 \text { months) } \\
\text { Increased esophageal } \\
\text { toxicity }\end{array}$ \\
\hline $\begin{array}{l}\text { Slotman et al. } \\
\text { (CREST study), } \\
2015[7]\end{array}$ & 495 & Phase III & $\begin{array}{c}\text { PE } \\
\text { (4-6 cycles) }\end{array}$ & $\mathrm{CT} \rightarrow \mathrm{RT}$ & $\begin{array}{l}30 \mathrm{~Gy} / 10 \mathrm{fr} \text { to residual } \\
\text { gross disease and } \\
\text { prechemotherapy } \\
\text { involved hilar and } \\
\text { mediastinal lymph } \\
\text { nodes }\end{array}$ & $\begin{array}{l}30 \mathrm{~Gy} / 12 \mathrm{fr} \\
25 \mathrm{~Gy} / 10 \mathrm{fr} \\
20 \mathrm{~Gy} / 5 \mathrm{fr}\end{array}$ & $\begin{array}{l}\text { Improved 2-year OS } \\
\text { (15\% vs. 3\%, } \mathrm{p}=0.004) ; \\
\text { no difference in 1-year OS }\end{array}$ \\
\hline $\begin{array}{l}\text { Gore et al. } \\
\text { (RTOG 0937), } \\
2017[8]\end{array}$ & 97 & Phase II & $\begin{array}{l}\text { Platinum- } \\
\text { based CT } \\
\text { (4-6 cycles) }\end{array}$ & CRT & $\begin{array}{l}45 \mathrm{~Gy} / 15 \mathrm{fr} \text { to disease } \\
\text { within the chest and } 1-4 \\
\text { oligometastatic lesions }\end{array}$ & $25 \mathrm{~Gy} / 10 \mathrm{fr}$ & $\begin{array}{l}\text { No difference in 1-year OS } \\
(60.1 \% \text { vs. } 50.8 \%, p=0.21)\end{array}$ \\
\hline
\end{tabular}

TRT: Thoracic radiotherapy; RCT: Randomized controlled trial; RT: Radiotherapy; CT: Chemotherapy; PCl: Prophylactic cranial radiotherapy; PE: Platinum etoposide; OS: Overall survival; ES-SCLC: Extensive-stage small cell lung cancer; RTOG: Radiation Therapy Oncology Group; CRT: Conformal radiotherapy; N: Number; fr: Fraction

SCLC patients. [6-8] The study by Jeremic et al. was the first study demonstrating the survival benefit of TRT.[6] The MSTs for the patients who did, and did not get TRT were 17 versus 11 months, respectively. Although phase III CREST study did not show any survival benefit for TRT at 1 year, 2 -year overall survival was $13 \%$ for the patients who received TRT and 3\% for the patients who did not ( $p=0.004)$. [7] In addition, progression-free survival and intra-thoracic progression were improved with TRT. The Radiation Therapy Oncology Group (RTOG) 0937 study did not show any difference with respect to the overall survival times at 1 year.[8] In 2016, the systematic review of two-phase III randomized studies by Jeremic et al. and Palma et al. was published.[9] In this systemic review, overall delivery of TRT was associated with improved overall survival and progression-free survival. The systemic review and meta-analysis of 3 randomized controlled trials were published by Rathod et al.[10] in 2019. This meta-analysis demonstrated that TRT significantly reduced thoracic progression as the first site of the failure and improved PFS benefit but did not offer a significant overall survival benefit. In the current study, the MST was 14 months (range: 12.6-15.3), and compatible with the literature data.

Interestingly, the radiation dose used in three randomized studies investigating the role of consolidative TRT in ES-SCLC patients was different from each other; therefore we have limited data with respect to the most appropriate RT doses. In the first study, Jeremic et al.[6] used accelerated hyperfractionated TRT with
54 Gy in 36 fractions over 18 treatment days and concurrent low-dose daily CT consisting of carboplatin and etoposide, $50 \mathrm{mg}$ each, given on each RT day, followed by PCI ( 25 Gy in 10 fractions) and then by two additional cycles of PE. In the CREST study, TRT was delivered to a dose of $30 \mathrm{~Gy}$ in ten fractions. [7] In this study all patients receive PCI, and PCI was given as 20 Gy in five fractions, 25 Gy in ten fractions, or 30 Gy in ten, 12, or 15 fractions. In the RTOG study, all patients received 25 Gy PCI at 2.5 Gy/fraction.[8] The TRT dose was $45 \mathrm{~Gy}$ delivered in 15 daily fractions of $3 \mathrm{~Gy}$; however, 30-40 was acceptable. Moreover, Li-Ming et al.[11] retrospectively evaluated 306 ES-SCLC patients, of which 170 received TRT. In this study, TRT biologically equivalent doses (BED) of $>50$ Gy improved overall survival times. In a study conducted from National Cancer Data Base, Hasan et al.[12] retrospectively analyzed 3280 stage IV ECLC patients who received TRT. Their results showed that patients who received $>45 \mathrm{~Gy}$ TRT had better survival. In the current study, the median dose of RT was $45 \mathrm{~Gy}$ (range: 30-66 Gy) applied in median 25 fractions (range: 10-34 fractions). In multivariate analysis, there was a trend towards overall survival times in patients who received $\geq 47$ Gy EQD2 doses; however, we believe that this statistical insignificance was related to our limited patient numbers.

Secondary analyses of the CREST study demonstrated that both the overall survival and progressionfree survival were significantly higher in patients with $\leq 2$ metastases. Moreover, patients with liver and bone 
metastases had significantly worse overall survival. [13] In the study by Jeremic et al.,[6] more than $90 \%$ of patients who undergone TRT had $<2$ metastases and did show overall survival benefit with TRT. The RTOG 0937 study included the patients with 1-4 metastases who had complete or partial response to CT; therefore, this study focuses on the oligometastatic patients. [8] In the RTOG 0937 study, the patients with brain metastasis were excluded. In can be concluded that the number of metastases is an important prognostic factor for benefit from TRT. In the current study, we could not demonstrate the impact of the number of metastases on survival. However, in our study, $62.9 \%$ of the patients had multiple metastases. We also did not include patients with brain metastases in our study.

The World Health Organization/ECOG performance status also could have an impact of TRT. The secondary analysis of the CREST study demonstrated that patients with better performance had improved overall, and progression-free survivals with TRT.[13] In the study by Jeremic et al., analyses of pretreatment factors also revealed that performance status was a strong prognostic factor.[6,14] Furthermore, in the RTOG 0937 study, there were some imbalances regarding to the performance status of the study groups that may be the reason for the lack of survival benefit. [8] Lastly, the analyses of pretreatment prognostic factors of the study by Jeremic et al.[14] revealed that various pretreatment prognostic factors including no significant weight loss were strong prognosticators of improved outcome. In the current study, we found that the unavailability of comorbid disease was associated with improved survival in ES-SLCL patients.

There is limited evidence with respect to the effect of gender on the impact of TRT in ES-SCLC patients. In the Dutch CREST study, the authors did not record any significant differences in OS in subgroups divided by age and sex.[7] In a retrospective study by $\mathrm{Xu}$ et al.,[15] it was found that there was no relationship between age, sex, and overall survival times. In the current study the MSTs for the female and male patients were 20 months, and 14 months, respectively.

PCI decreases the incidence of symptomatic brain metastases for the ES-SCLC patients who responded to systemic CT; however, its impact on overall survival is uncertain. In a phase III trial conducted by the European Organization for Research and Treatment of Cancer, all patients initially received four to six cycles of $\mathrm{CT}$, and patients with a response to CT were randomly assigned to PCI or to observation without PCI.[5] Patients were not routinely imaged for the presence or absence of brain metastases after CT and prior to PCI. The PCI doses were between 20 and 30 Gy, applied between 5 and 12 fractions. Patients treated with PCI had a significantly decreased incidence of symptomatic brain metastases at 1 year. The median overall survival was increased in patients treated with PCI (6.7 vs. 5.4 months, measured from randomization), and the 1 -year survival rate was significantly increased. On the other hand, a Japanese phase III trial in ES-SCLC patients comparing PCI plus magnetic resonance imaging (MRI) surveillance versus MRI surveillance failed to demonstrate a difference in PFS or OS between the two strategies.[16] In the current study, we demonstrated that ES-SCLC patients who received PCI had improved survival times.

In the current study, we did not encounter unexpected hematological, and non-hematological toxicities. The treatment was well tolerated. In the study by Jeremic et al., severe esophageal toxicity was encountered; however, in this study 2-dimensional conformal RT technique, larger treatment fields, and accelerated hypofractionated RT schedule were used.[6,14] In the CREST study, although esophageal toxicity was increased with the use of TRT, $\geq$ grade 3 esophageal toxicity in the TRT arm remained uncommon. Bronchopulmonary toxicity (grade 3 or higher) was similar in both TRT and non-TRT groups. [7] In the RTOG study, the differences between the TRT and non-TRT groups were not significant.[8] One patient in each arm had grade 4 toxicity, and one patient in PCITRT had grade 5 pneumonitis. Taken these all together it seems that the use of TRT is safe when applied with more conformal techniques, and limited treatment fields.

There are some limitations to our study that should be mentioned. First and foremost, the current study has a retrospective design and limited patient numbers. The different centers used their own protocols. Ten out of 151 patients $(6.6 \%)$ received RT prior to CT because of vena cava superior syndrome. Therefore, we could not assess CT response for these patients. Besides these limitations, the current study's strengths include a longer follow-up period and its multi-centric nature.

\section{Conclusion}

The use of consolidative TRT is reasonable in patients who responded to CT. Female gender, use of PCI, and unavailability of comorbid disease were associated with improved survival in ES-SLCL patients. There was a trend towards overall survival times in patients who received $\geq 47$ Gy EQD2 doses; however, we be- 
lieve that this statistical insignificance was related to our limited patient numbers. Further research studies to identify the patients who are likely to have more OS benefit, the optimal dose fractionation schedule of TRT, the optimal timing of TRT, and the optimal CTTRT sequence are needed.

Peer-review: Externally peer-reviewed.

Conflict of Interest: All authors declared no conflict of interest.

Ethics Committee Approval: Retrospective study.

Financial Support: This study has received no financial support.

Authorship contributions: Concept - G.Y., S.A., M.S., F.Ö.D.; Design - G.Y., S.A., M.S., F.Ö.D.; Supervision - G.Y., S.A., E.T., F.Ö.D., M.S.; Funding - None; Materials - G.Y., S.D.B., Y.Ö., Ç.Y., E.K.K., M.D.; Data collection and/or processing - G.Y., S.D.B., Y.Ö., Ç.Y., E.K.K., M.D., E.T., S.A.; Data analysis and/or interpretation - E.T., Y.Ö., G.Y.; Literature search - G.Y., Ç.Y.; Writing - G.Y., S.A.; Critical review - G.Y., S.A., E.T.

\section{References}

1. van Meerbeeck JP, Fennell DA, de Ruysscher DK. Smallcell lung cancer. Lancet 2011;378(9804):174155.

2. Houston KA, Henly SJ, Li J, White MC, Richards TB. Patterns in lung cancer incidence rates and trends by histologic type in the United States, 2004-2009. Lung Cancer 2014;86(1):22-8.

3. Früh $M$, de Ruysscher D, Popat $S$, Crinò L, Peters $S$, Felip E, et al. Small-cell lung cancer (SCLC): ESMO clinical practice guidelines for diagnosis, treatment and follow-up. Ann Oncol 2013;24 Suppl 6:vi99-105.

4. Byers LA, Rudin CM. Small cell lung cancer: Where do we go from here? Cancer 2015;121(5):664-72.

5. Slotman BJ, Faivre-Finn C, Kramer G, Rankin E, Snee $M$, Hatton $M$, et al. Prophylactic cranial irradiation in extensive small-cell lung cancer. N Engl J Med 2007;357(7):664-72.

6. Jeremic B, Shibamoto Y, Nikolic N, Milicic B, Milisavljevic $S$, Dagovic A, et al. Role of radiation therapy in the combined-modality treatment of patients with extensive disease small-cell lung cancer: A randomized study. J Clin Oncol 1999;17(7):2092-9.

7. Slotman BJ, van Tinteren H, Praag JO, Knegjens JL,
El Sharouni SY, Hatton M, et al. Use of thoracic radiotherapy for extensive stage small-cell lung cancer: A phase 3 randomised controlled trial. Lancet 2015;385(9962):36-42.

8. Gore EM, Hu C, Sun AY, Grimm DF, Ramalingam SS, Dunlap NE, et al. Randomized Phase II study comparing prophylactic cranial irradiation alone to prophylactic cranial irradiation and consolidative extra-cranial irradiation for extensive disease small cell lung cancer (ED-SCLC): NRG oncology RTOG 0937. J Thorac Oncol 2017;12(10):1561-70.

9. Palma DA, Warner A, Louie AV, Senan S, Slotman B, Rodrigues GB. Thoracic radiotherapy for extensive stage small-cell lung cancer: A meta-analysis. Clin Lung Cancer 2016;17(4):239-44.

10. Rathod S, Jeremic B, Dubey A, Giuliani M, Bashir B, Chowdhury A, et al. Role of thoracic consolidation radiation in extensive stage small cell lung cancer: A systematic review and meta-analysis of randomized controlled trials. Eur J Cancer 2019;110:110-9.

11. Li-Ming X, Zhao LJ, Simone CB $2^{\text {nd }}$, Cheng C, Kang $\mathrm{M}$, Wang $\mathrm{X}$, et al. Receipt of thoracic radiation therapy and radiotherapy dose are correlated with outcomes in a retrospective study of three hundred and six patients with extensive stage small-cell lung cancer. Radiother Oncol 2017;125(2):331-7.

12. Hasan S, Renz P, Turrisi A, Colonias A, Finley G, Wegner RE. Dose escalation and associated predictors of survival with consolidative thoracic radiotherapy in extensive stage small cell lung cancer (SCLC): A national cancer database $(\mathrm{NCDB})$ propensity-matched analysis. Lung Cancer 2018;124:283-90.

13. Slotman BJ, Faivre-Finn C, van Tinteren H, Keijser A, Praag J, Knegjens J, et al. Which patients with ESSCLC are most likely to benefit from more aggressive radiotherapy: A secondary analysis of the Phase III CREST trial. Lung Cancer 2017;108:150-3.

14. Jeremic B, Gomez-Caamano A, Dubinsky P, Cihoric N, Casas F, Filipovic N. Radiation therapy in extensive stage small cell lung cancer. Front Oncol 2017;7:169.

15. Xu LM, Cheng C, Kang M, Luo J, Gong LL, Pang QS, et al. Thoracic radiotherapy (TRT) improved survival in both oligo-and polymetastatic extensive stage small cell lung cancer. Sci Rep 2017;7(1):9255.

16. Takahashi T, Yamanaka T, Seto T, Harada H, Nokihara $\mathrm{H}$, Saka $\mathrm{H}$, et al. Prophylactic cranial irradiation versus observation in patients with extensive-disease smallcell lung cancer: A multicentre, randomised, open-label, phase 3 trial. Lancet Oncol 2017;18(5):663-71. 